\title{
Ciência do Esporte no Brasil: reflexões sobre o desenvolvimento das pesquisas, o cenário atual e as perspectivas futuras
}

CDD. 20.ed. 001

796.073

http://dx.doi.org/10.1590/1807-55092015000100163

\author{
Luís VIVEIROS S $^{* * * * *}$ \\ Alexandre MOREIRA** \\ David BISHOP ${ }^{* * *}$ \\ Marcelo Saldanha AOKI****
}

*Centro de Ciências
Biológicas e da Saúde,
Universidade Federal
do Estado do Rio de
Janeiro.
**Escola de Educa-
ção Física e Esporte,
Universidade de São
Paulo.
***Institute of Sport,
Exercise and Active
Living, Victoria Unive-
sity - Australia.
****Escola de Artes,
Ciências e Humanida-
des, Universidade de
São Paulo.

\section{Introdução}

O Brasil vive um momento ímpar em relação ao Esporte, uma vez que sediou, recentemente, a Copa do Mundo da FIFA (2014) e, em 2016, os Jogos Olímpicos serão realizados na Cidade do Rio de Janeiro. As oportunidades associadas a esses megaeventos são imensas nos mais diversos setores. No âmbito da pesquisa científica, seria desejável que a realização dos eventos esportivos mais importantes do mundo também impulsionasse o desenvolvimento da Ciência do Esporte no país. Levando em consideração esse cenário favorável, é imprescindível uma reflexão sobre a investigação científica no contexto do Esporte. Assim, os objetivos deste ensaio são: revisitar o modelo teórico para o desenvolvimento da Ciência do Esporte proposto por Bishop ${ }^{1}$, apresentar o panorama da Ciência do Esporte no Brasil e discutir diretrizes e perspectivas futuras.

\section{O que é Ciência do Esporte?}

A Ciência do Esporte abrange diversas áreas do conhecimento que visam entender e otimizar o desempenho esportivo. A Ciência do Esporte pode ser definida como o processo científico utilizado para orientar/guiar a prática esportiva, visando o alcance do desempenho máximo ${ }^{1-2}$. A investigação no âmbito esportivo tem (ou deveria ter) como finalidade principal a utilização do conhecimento científico, considerando a melhor evidência disponível, no ambiente apropriado, para um determinado atleta (ou grupo de atletas), com intuito de maximizar o seu desempenho ${ }^{1}$. Com relaçáo ao papel do cientista do Esporte, vale a pena destacar a 
recente definição proposta por CouTTs" : "promover a inovação com a expectativa de que isso se traduza em uma vantagem competitiva." Essa definição, apesar de simples, esclarece apropriadamente a função do cientista do Esporte. Porém, se a definição do papel exercido é relativamente simples, essa tarefa, por outro lado, é extremamente complexa. A fim de se garantir que as evidências sejam levadas a cabo no dia a dia de atletas, treinadores e profissionais envolvidos no contexto esportivo, é imperativo que estudos bem delineados sejam conduzidos e os seus resultados sejam colocados em prática no cotidiano do Esporte ${ }^{1-2}$.

\section{Qual o impacto da Ciência do Esporte sobre o cotidiano do Esporte?}

Esse questionamento acima incita o velho dilema: teoria vs. prática. Não somente na área do Esporte, mas também em outras áreas do conhecimento, parece haver um consenso que a transferência do conhecimento científico para a prática ainda é muito baixa. Um exemplo, na área das ciências da saúde, que pode ser utilizado para ilustrar a presente discussão, é o da Psicologia. Em um estudo recente ${ }^{4}$, realizado na Inglaterra, 736 psicólogos responderam um questionário eletrônico sobre as suas condutas clínicas. No referido estudo, foi constatado que a pesquisa científica tem pouca influência sobre os processos de orientação teórica e tomada de decisão referentes à prática clínica, em comparação a outros fatores (ex. experiência clínica e supervisão). Outra área que apresenta um cenário similar é a Enfermagem. Ajani e MoEz ${ }^{5}$ conduziram uma revisão de literatura e reconheceram a existência de um "gap" entre o conhecimento científico e a prática da Enfermagem. Diante do referido cenário, estes autores apresentaram recomendaçóes para minimizar a distância entre a teoria e a prática. Primeiro, 1) inserir os professores/ educadores na prática clínica, com intuito de reforçar suas habilidades clínicas e vivenciar o cotidiano do enfermeiro; segundo 2) promover o intercâmbio e a troca de experiências entre o professor/educador e o profissional do campo (enfermeiro). Nesse sentido, um modelo que vem sendo testado em algumas instituiçôes, tem como base a contratação de profissionais que são alocados nas duas posiçôes (professor e enfermeiro) por determinados períodos de tempo. $\mathrm{O}$ professor/educador atua como enfermeiro durante um ano e o enfermeiro como educador no ano seguinte. E finalmente, outra recomendação importante feita pelos pesquisadores é: 3) reestruturar a formação universitária e estimular a educação continuada no ambiente de trabalho. $\mathrm{O}$ aprendizado baseado em problema e a prática baseada em evidência, incitando o pensamento crítico, são ressaltados como estratégias que devem ser mais incentivadas.
A relação entre a Ciência do Esporte e os treinadores também foi objeto de investigação ${ }^{6-7}$. Apesar da crença de que a Ciência do Esporte não atende as necessidades da prática, William e Kendall ${ }^{6}$ verificaram congruência entre cientistas e treinadores em alguns aspectos. Ambos os grupos têm a mesma percepção sobre a importância e a aplicação da pesquisa científica; concordam sobre a metodologia para determinar as perguntas das pesquisas e convergem em relação às competências que treinadores e cientistas deveriam apresentar para atuar no âmbito esportivo. Entretanto, os treinadores acreditam que existe a necessidade de realizar mais pesquisas na área da Psicologia do Esporte. Além disso, esses profissionais destacam que esse conhecimento precisa ser divulgado de forma mais acessível.

Em outro estudo na área do Esporte, READE et al. ${ }^{7}$ buscaram respostas para importantes perguntas relacionadas a esse contexto, aplicando um questionário estruturado composto por 33 itens, delineado para examinar como o conhecimento produzido pela pesquisa em Esporte era transferido para os treinadores de elite no Canadá. Duzentos e cinco treinadores canadenses responderam ao questionário, reconhecendo a importância da ciência

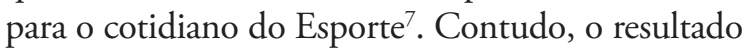
do estudo também demonstrou a existência de lacunas entre as necessidades dos treinadores e o que tradicionalmente é pesquisado na área, especialmente no que concerne aos aspectos técnicos e táticos ${ }^{7}$. Os treinadores apontaram ser mais inclinados a buscar informação com outros treinadores ou através de participações em conferências de treinadores, ao passo que os pesquisadores do Esporte e suas publicaçóes foram "ranqueados" em nível inferior como fontes de informação ${ }^{7}$. As principais barreiras ressaltadas pelos treinadores para o acesso ao conhecimento científico foram o tempo requerido tanto para identificar os artigos, quanto para lê-los ${ }^{7}$. Além disso, a falta de acesso direto aos pesquisadores foi destacada como 
outra importante barreira. É importante destacar que esses países (Austrália e Canadá) encontram-se em outro estágio nesta relação entre a Ciência do Esporte e o cotidiano de treinadores e atletas, em comparação ao Brasil, mas mesmo assim, ainda enfrentam limitaçôes na aplicação do conhecimento científico no contexto prático.

A dificuldade encontrada pelos treinadores, relatada nos estudos anteriormente citados, referente ao acesso e leitura de artigos científicos precisa ser considerada. Vale ressaltar que atualmente a principal forma de divulgação científica é a publicação de artigos, geralmente, em revistas indexadas, com acesso relativamente restrito. Esse fato dificulta o acesso à informação por parte dos profissionais que atuam na prática. Ainda há outro agravante para os treinadores brasileiros, pois grande parte das publicaçóes é realizada em língua inglesa, inclusive, por parte de vários pesquisadores brasileiros e seus grupos de pesquisa. Esta questão, inclusive, foi uma das principais motivaçôes para a confecção desse ensaio, justamente no sentido de facilitar a disseminação das informações sobre o modelo de investigação em Ciência do Esporte, proposto por Bishop ${ }^{1}$ (que gentilmente concordou em participar dessa releitura do seu modelo), utilizando a língua portuguesa. Dessa forma, a barreira do idioma seria minimizada, aumentando as chances de acesso ao conteúdo do modelo, por parte dos treinadores, atletas, estudantes de graduação, entre outros.

Se por um lado (o dos profissionais do Esporte) o acesso à informação é uma limitação, do outro lado (cientistas do Esporte) observa-se outro problema em relação à informação. Recentemente CouTts ${ }^{3}$, ilustra em seu editorial, publicado no International Journal of Sports Physiology and Performance, o impacto do avanço tecnológico sobre o cenário atual da Ciência do Esporte. Esse pesquisador ressalta que na era da tecnologia, com a crescente utilização de diversos dispositivos e equipamentos (receptores para o GPS, monitores de frequência cardíaca, acelerômetros, lactímetros, leitores de ELISA, etc), os cientistas tem acumulado "toneladas" de dados e informaçóes. Entretanto, os mesmos não tem tempo para analisálos, interpretá-los, e mais importante, apresentá-los para a comissão técnica de uma forma que esses dados possam modificar positivamente a prática diária. CoutTs ${ }^{3}$ ainda enfatiza que mesmo na era da tecnologia, com todos os avanços experimentados, o "Princípio da Navalha de Occam" continua válido. Para esse pesquisador, o uso de ferramentas mais simples (como a Escala de percepção do esforço, por exemplo) pode fornecer informaçóes tão válidas e valiosas sobre a magnitude do esforço do treinamento quanto às disponibilizadas por outros equipamentos mais sofisticados. Vale ressaltar que esses equipamentos e essas análises são caros e nem sempre estão disponíveis para a comissão técnica na rotina do treinamento.

Atualmente, é possível afirmar que a contribuição da Ciência do Esporte para orientação da prática no Esporte é ainda pequena. Alguns dados disponíveis na literatura também sugerem que a influência da Ciência do Esporte para a atuação de técnicos e preparadores físicos é insípida ${ }^{1-2}$. Possivelmente, a forma como as pesquisas têm sido direcionadas contribui também para a baixa transferência do conhecimento gerado pelos pesquisadores do Esporte para a prática profissional. Ou ainda, o modelo de pesquisa e os interesses plurais dos pesquisadores, muitas vezes distantes das demandas e necessidades do cotidiano do Esporte, também dificultam a produção de conhecimento com potencial de orientar a prática. Nesse sentido, o desenvolvimento e a aplicação de modelos teóricos que direcionem as açôes futuras e aumentem as chances de contribuição efetiva para o Esporte são imprescindíveis. Diante dessa necessidade, o primeiro objetivo do presente ensaio é revisitar o modelo teórico para a pesquisa no Esporte. Este modelo, proposto por Bishop ${ }^{1}$, é constituído de oito estágios, que serão abordados brevemente nos próximos tópicos.

\section{Modelo teórico para o desenvolvimento da pesquisa científica aplicada ao Esporte}

Em 2008, foi publicado um modelo teórico para o desenvolvimento de pesquisas no Esporte ${ }^{1}$. Este modelo, proposto por BisHOP ${ }^{1}$, será brevemente apresentado neste tópico. A ideia central desse modelo é reduzir a distância entre o conhecimento científico e a prática, visando assim, em última instância, contribuir com a melhora do desempenho esportivo. Esse modelo contempla diferentes etapas. As oito etapas do modelo são: 1) caracterização do problema; 2) realização de pesquisas descritivas; 3 ) 
identificação dos fatores preditores do desempenho; 4) experimentação dos preditores do desempenho; 5) determinação dos principais fatores preditores do desempenho; 6) realização de estudos de eficácia; 7) avaliação das barreiras para adoção; e 8) implementação do conhecimento no ambiente esportivo real.

\section{Fase 1 - Caracterização do problema}

Para a primeira fase proposta por $\mathrm{BISHOP}^{1}$, o referido autor faz uma importante consideração e ressalta que apesar de essa fase parecer óbvia e reconhecida como essencial pela maioria dos pesquisadores, é possível encontrar na literatura diversos estudos que, ao contrário do proposto, tiveram sua origem baseada, exclusivamente, na conveniência da coleta de dados e na possibilidade de publicaçáo. Esses estudos, portanto, não seguiram o modelo de pesquisa orientado para resoluçáo de problemas. $\mathrm{O}$ modelo proposto por BisHOP ${ }^{1}$ sugere que o pesquisador compreenda os problemas reais enfrentados por treinadores, preparadores físicos e atletas. Nesse sentido, se possível, seria muito proveitoso que o pesquisador tivesse vivenciado o Esporte em algum momento da sua vida. O pesquisador também deveria considerar a experiência de treinadores e atletas, a fim de priorizar os problemas a serem abordados.

Fase 2-Realização de pesquisas descritivas

A grande maioria dos estudos disponíveis relacionados à Ciência do Esporte apresenta caráter descritivo. Bishop ${ }^{1}$ acredita que, provavelmente, isso tenha relação direta com a questão do fácil acesso aos dados, ao invés da orientação para resolução de problemas. No entanto, estudos exploratórios/ descritivos são fundamentais para o levantamento de informaçôes sobre as condiçóes, nas quais o Esporte em questáo é realizado, sob os mais diferentes aspectos e dimensôes. Assim, após a identificação do problema (Fase 1), a realização de pesquisas descritivas poderia fornecer suporte para as fases subsequentes do modelo. Estas pesquisas, por sua vez, deveriam incluir estudos que tracem perfis e relatos que descrevam o que efetivamente está acontecendo no âmbito específico (por exemplo, dados antropométricos, características fisiológicas e psicológicas, ingestão alimentar, análise de movimento, rotinas de treinamentos, estratégias de recuperação, entre outros). Bishop ${ }^{1}$ ressalta que este tipo de pesquisa é a base para os próximos estágios, servindo também para incitar novos questionamentos. Além das pesquisas já realizadas, é pertinente reconhecer que ainda existem muitos dados não publicados neste estágio do modelo. É importante, portanto, que estas pesquisas continuem sendo desenvolvidas e os dados publicados, a fim de ampliar o panorama referente ao Esporte em questão. Além disso, é fundamental promover o maior acesso a estas informaçôes, tanto por parte da comunidade científica, quanto dos profissionais envolvidos no cotidiano do Esporte. Entretanto, vale mencionar que muitos periódicos, por vezes, são resistentes em publicar este tipo de pesquisa, estritamente descritiva, alegando baixa originalidade e contribuição para a área. Essa resistência pode ser considerada uma ameaça ao desenvolvimento do corpo de conhecimento da área da Ciência do Esporte, pois apesar da importância desse tipo de informação descritiva, pesquisadores podem ser desestimulados, caso a rejeição para esse tipo de investigação seja elevada. Os editores e revisores dos periódicos da área deveriam entender e reconhecer essa particularidade do fenômeno Esporte, assim estes poderiam diminuir sua resistência, pois, é evidente que essas pesquisas podem apresentar originalidade e contribuição relevante para a área.

Alguns importantes periódicos tem estimulado e valorizado esse tipo de publicação, por reconhecerem a relevância dos dados gerados para o aumento do conhecimento relativo à Ciência do Esporte. Essa sinalização indica, claramente, que apesar de opinióes contrárias, estas pesquisas podem apresentar ainda grande contribuiçáo para a área e trazer para a comunidade resultados originais e pertinentes. Por exemplo, recentemente, Moreira et al. ${ }^{8}$ publicaram um artigo intitulado "The training periodization of professional Australian Football players during an entire AFL season" no International Journal of Sport Physiology and Performance. O objetivo desse estudo foi examinar a periodização de atletas de elite de Futebol Australiano, durante diferentes fases da temporada ${ }^{8}$. A referida investigação, de caráter descritivo, propiciou estender o conhecimento acerca da carga de treinamento implementada ao longo de 45 semanas da temporada competitiva, de 44 jogadores, com ênfase no relato sobre a distribuiçâo do volume e intensidade de treinamento, características e tipos de sessóes de treinamento ${ }^{8}$. Além disso, foram descritas a carga resultante da participação em jogos oficiais, as diferenças entre a carga de treinamento e a carga de competição por posiçâa, as diferenças na carga de treinamento semanal para distintos períodos de recuperação entre jogos, as zonas de intensidade de carga para os distintos tipos de sessóes de treinamento, entre outras informaçôes importantes ${ }^{8}$. 
Este tipo de pesquisa, por exemplo, pode auxiliar pesquisadores do Esporte, treinadores e preparadores físicos, a melhor compreender a periodização do treinamento realizada em um dado Esporte, e assim, otimizar a sua organização. Essa mesma abordagem poderia ser aplicada em outras modalidades como, por exemplo, no Futebol, Futsal, Basquetebol, Voleibol, entre outros. Esse tipo de informação poderia auxiliar, de forma considerável, o avanço do conhecimento sobre as práticas de organização e monitoramento do processo de treinamento esportivo.

\section{Fase 3-Identificação dos fatores preditores do desempenho (Estudos de regressão)}

A segunda fase é fundamental, pois os achados descritivos poderiam apontar o caminho para a solução dos problemas. Já, a terceira fase envolveria pesquisa focada na melhor compreensão dos fatores que podem afetar o desempenho. Via de regra, essa fase é caracterizada pela investigação das relaçôes entre variáveis preditoras e desempenho esportivo real. No modelo proposto, estes resultados seriam a base dos estudos subsequentes de caráter experimental; segundo BisHop ${ }^{1}$ somente após a identificação dos fatores específicos a serem modificados e as possibilidades para modificá-los, as possíveis intervençóes poderão ser planejadas e, assim, futuramente, implementadas.

É importante ressaltar que tais estudos não irão elucidar mecanismos de açáo. $\mathrm{O}$ foco dessas pesquisas seria prover informaçóes relevantes sobre os fatores que poderiam ser modificados para melhorar o desempenho esportivo real. Conforme relatado por BisHOP ${ }^{1}$, quanto maior for a associação entre cada variável e desempenho esportivo real, maior será a probabilidade de que qualquer relaçáo observada seja causal. Entretanto, é preciso analisar esses resultados com extrema cautela e parcimônia. É recomendado por BisHop ${ }^{1}$ que os pesquisadores considerem os intervalos de confiança e o tamanho da amostra. Caso haja uma relação causal verdadeira, seria esperado que essas relaçôes fossem replicadas em outros estudos e com outras amostras, em condiçóes e situaçóes variadas. Infelizmente, é improvável que isso ocorra. Como resultado da ênfase em "novas descobertas" adotada pela maioria dos periódicos, esta etapa crucial da replicação e confirmação dos resultados originais raramente ocorre. Mais uma vez, é fundamental conscientizar os editores e revisores dos periódicos da área sobre a relevância dessa replicação de resultados.
Embora, aceitando a necessidade de incentivar a pesquisa original, os pesquisadores da Ciência do Esporte também deveriam tentar reproduzir os achados anteriores em seus novos estudos (por exemplo, investigar e relatar as correlações identificadas anteriormente junto com os novos aspectos de seus estudos). Relaçóes identificadas de forma consistente, alinhadas com o conhecimento existente e replicadas em diferentes condições e amostras, estão mais propensas a estabelecer relação causa-efeito em ambiente real de treinamento e competição. No entanto, mesmo se todo o exposto for verdadeiro, os pesquisadores, em colaboração com treinadores e atletas, deveriam considerar explicaçóes alternativas para as relaçóes observadas. Bishop ${ }^{1}$ aponta que estes dois últimos pontos exigem conhecimento teórico-prático sobre a área e os fatores que poderiam influenciar o desempenho esportivo. No entanto, é importante lembrar que mesmo quando todos os fatores acima são considerados, os estudos de regressão apenas fornecem evidências de relaçóes casuais. A realização de estudos experimentais para testar essas relaçóes deve ser fomentada e desenvolvida nas seguintes etapas do modelo.

Existem vários exemplos de pesquisa no esporte que utilizaram a "fase 3" em suas abordagens experimentais (estudos de regressão) que poderiam ser utilizados para ilustrar a fase em questáo. Por exemplo, o estudo publicado por VANDORPE et al. ${ }^{9}$, no qual 23 ginastas do sexo feminino foram analisadas durante dois anos. O objetivo do estudo era identificar quais características eram relacionadas com o desempenho competitivo propriamente dito9. Estas ginastas, de 7-8 anos de idade, completaram uma bateria de testes que incluía medidas antropométricas, testes físicos, testes coordenativos e caraterísticas técnicas avaliadas pelos treinadores. Os pesquisadores relataram que os testes de coordenação motora se mostraram bons preditores do desempenho e discriminaram o nível das atletas". A conclusão do estudo, portanto, sugere que os testes de coordenação motora (gerais) podem ser importantes para a identificação precoce das ginastas ${ }^{9}$. Adicionalmente, é sugerido pelo estudo que estes testes poderiam ser utilizados nos processos de seleção, em populaçóes relativamente homogêneas de ginastas, as quais exibem perfis semelhantes, tanto no que tange aos aspectos antropométricos quando no que se refere ao perfil físico?.

A busca pelo avanço no entendimento do valor preditivo e discriminatório de testes e medidas está amplamente associada aos objetivos da fase 3. O conhecimento gerado nesta fase poderia ser utilizado nas fases seguintes, notadamente, na experimentação 
dos preditores do desempenho. Recentemente, uma pesquisa conduzida por Moreira et al. (dados náo publicados) investigou a influência do nível de maturação, das medidas antropométricas e da aptidão física no desempenho em jogos reduzidos de 30 jovens jogadores de futebol, pertencentes a um dos mais importantes clubes de Futebol do Brasil. A concentração de testosterona salivar, as medidas antropométricas, o nível de maturaçáo sexual e o desempenho em testes de potência muscular e resistência à fadiga foram as variáveis independentes selecionadas. A análise fatorial foi utilizada para identificar as variáveis mais representativas que poderiam ser utilizadas em uma análise multivariada subsequente. Para verificar a predição do desempenho técnico (múltiplas variáveis dependentes), utilizandose das variáveis extraídas da análise de componentes principais, uma análise de correlação canônica multivariada foi conduzida, considerando, portanto, dois "sets" de variáveis e não as variáveis isoladamente. O principal resultado do estudo foi a fraca relação entre o conjunto de variáveis formado pelo perfil hormonal, medidas antropométricas, nível de maturação e desempenho físico e o conjunto de variáveis de desempenho nos jogos reduzidos. Esses dados sugerem que os fatores preditores utilizados no estudo não são suficientemente robustos para explicar o desempenho específico em jogos reduzidos de Futebol para esta população. Este resultado também sugere que para uma amostra homogênea de jovens jogadores, as características hormonais, maturacionais, antropométricas e físicas não influenciam o desempenho nos jogos reduzidos.

\section{Fase 4 - Experimentação dos preditores do desempenho}

O quarto estágio do modelo envolve a verificação dos fatores, previamente identificados na fase 3, e a busca pelo melhor entendimento da influência desses aspectos sobre o desempenho esportivo. Uma vez demonstrada a associação (fase 3 ), a condução destes estudos seria importante para determinar se essa associação é de fato causal. Tipicamente, este tipo de investigação envolve a manipulação de uma variável (durante a tentativa de controlar ou combinar as outras variáveis) e a medição do efeito subsequente sobre o desempenho. A realização de estudos randomizados, duplo-cegos (com uma condição placebo ou controle) seria a condição ideal, quando possível, para esta finalidade. No entanto, conforme explicado por Bishop ${ }^{1}$, os resultados destes estudos também devem ser interpretados com cautela, pois é muito difícil controlar todas as variáveis que podem influenciar as relaçóes anteriormente observadas, particularmente no "mundo real" do Esporte. Além disso, os resultados podem ser específicos para a população avaliada, o que implica em uma análise com reconhecimento desta limitação.

Reconhecendo a possibilidade de esses resultados expressarem somente uma resposta específica para determinado grupo, como por exemplo, nos estudos com uma equipe ou mesmo categorias (faixas etárias distintas) de um mesmo clube, Bishop ${ }^{1}$ ressalta que estes dados deveriam ser analisados com parcimônia dada a dificuldade de se controlar todas as variáveis que podem influenciar as relaçóes observadas no "mundo real" do Esporte. No entanto, Bishop ${ }^{1}$ destaca que é igualmente importante entender a relevância e pertinência desse tipo de investigação, bem como, as possibilidades de avanço que os resultados destes estudos podem trazer para a área especifica.

Adicionalmente, a inclusão de condiçóes placebo ou grupo controle em experimentos no ambiente esportivo, é extremamente difícil de ocorrer e, considerada, por STONE et al. ${ }^{10}$ como antiética. É razoável admitir que a proposição de STONE et al. ${ }^{10}$, considerando a inclusão de condiçôes placebo ou grupo controle como possivelmente "antiética", esteja relacionada ao fato do pesquisador, previamente, baseado em resultados de pesquisas e experiências anteriores, levantar a hipótese de que um determinado protocolo de treinamento tenha grandes chances de induzir incremento no desempenho e que a condição controle, por outro lado, apresente grandes chances de não afetar o desempenho. A questáo central aqui, obviamente, é o quão ético seria propor a inclusão de um grupo controle, considerando o aumento do risco para os sujeitos da amostra, que no caso, seria a estagnação ou deterioração do desempenho. $\mathrm{O}$ quão ético isto seria? Qual a chance real do pesquisador conseguir desenvolver este projeto em uma equipe de alto nível, que irá participar de uma competição oficial ao final do experimento, ou mesmo, durante a condução do experimento? Será que uma alternativa náo seria a conduçáo do experimento em diferentes equipes e a subsequente avaliaçáo dos efeitos do modelo proposto sobre as variáveis e atributos importantes para o desempenho, mesmo reconhecendo-se que não seriam comparados diferentes modelos de intervenção, mas sim, o efeito daquela intervenção em uma amostra que efetivamente representa a populaçáo de interesse? Será que não é o momento da comunidade reconhecer a importância deste tipo 
de estudo, ao invés de assumir que tal fato é uma "fragilidade" metodológica, por não contar com o grupo placebo ou o grupo controle? Será que a manutenção desta forma de pensamento não limita o avanço da Ciência do Esporte e ignora a natureza específica desta área?

\section{Fase 5 - Determinação dos principais fatores preditores do desempenho}

Esta fase tem como objetivo determinar a melhor intervenção para alterar/influenciar o fator preditor escolhido. Essa fase deveria ser fortemente orientada pelos dois estágios anteriores, nos quais os fatores que afetam o desempenho foram identificados e testados experimentalmente. Caso contrário, os pesquisadores podem fazer um grande esforço de investigação (provavelmente até muito interessante) que estabelece o melhor método para alterar um fator que náo afeta o desempenho esportivo. Bishop ${ }^{1}$ ressalta que em muitos casos, uma linha de pesquisa poderia ter início a partir dessa fase, uma vez que outros pesquisadores já tenham estabelecidos os principais fatores que potencialmente afetariam o desempenho. Esta fase poderia incluir a realizaçáo de muitos estudos controlados para determinar a melhor intervenção (frequência, tipo, duração, etc) capaz de alterar o fator preditor de desempenho escolhido. A palavra "intervenção" é usada em seu sentido mais amplo e pode referir-se: à formação, à orientação nutricional, à alteração técnica, aos métodos de treinamento, etc. Para BisHop ${ }^{1}$, pesquisas visando determinar os mecanismos causais responsáveis pelas mudanças nas variáveis preditoras escolhidas também poderiam fazer parte desta fase. Uma vez que a melhor intervenção foi identificada (frequentemente com base nos resultados de muitos estudos realizados por diferentes grupos de pesquisa), os estudos de eficácia (fase 6) poderiam, então, ser realizados para determinar o efeito da alteraçáo de uma variável preditora no desempenho real.

\section{Fase 6 - Realização de estudos de eficácia}

Os ensaios de eficácia podem ser definidos como testes para avaliar se uma determinada intervenção exerce efeito substancial (positivo ou negativo) sobre o desempenho esportivo em condições reais. Para Bishop $^{1}$, os ensaios de eficácia são caracterizados por rigoroso controle das variáveis, nos quais a intervenção padronizada é aplicada de forma uniforme e controlada para uma população específica, homogênea e motivada. Esta abordagem deveria incluir a seleção aleatória dos participantes, a atribuição aleatória de condições e (se possível) o uso de placebos (idealmente duplo-cego) ou delineamentos do tipo cruzado. Estudos altamente controlados, realizados em situações de campo, também deveriam ser conduzidos neste estágio, uma vez que, a maioria destes estudos é realizada em um "ambiente artificial" que inclue recursos (e restriçóes) que muitas vezes não estão disponíveis para treinadores e atletas. Devido à padronizaçáo e controle rigoroso dos ensaios de eficácia, qualquer efeito substancial (ou negativo) poderia ser mais fortemente atribuído à intervenção. Essa abordagem reducionista (que isola, remove ou controla outros fatores) tem contribuído muito para o avanço da ciência, a despeito da limitação do enfoque fragmentado para a generalização dos resultados.

Estes estudos poderiam gerar resultados de pesquisas muito interessantes. No entanto, essa pesquisa é muitas vezes criticada por não ser transferível para o campo ou para o "mundo real". Segundo Bishop ${ }^{1}$, a necessidade de controle rígido também poderia levar ao desenvolvimento de intervençóes que têm uma menor probabilidade de sucesso no "mundo real”. Esta fase é, portanto, essencial para avaliar intervençôes potenciais no campo, mas por outro lado, os pesquisadores, treinadores e atletas deveriam reconhecer sua limitaçáo no âmbito da abordagem reducionista. A investigaçáo subsequente, particularmente para a fase 8 , é fundamental para determinar se o efeito da intervençáo é suficientemente potente para fazer uma diferença na situaçáo real.

\section{Fase 7 - Avaliação das barreiras para adoção}

Embora haja exceçôes, os pesquisadores muitas vezes não compreendem e não consideram muitas questôes que restringem/limitam o trabalho dos profissionais do Esporte. Estes profissionais têm de lidar com lesóes, nível de motivação, necessidade de recuperação, doenças, calendário de competiçôes, tempo insuficiente, falta de equipamento ou experiência para executar o programa como testado na situação experimental controlada. Conforme Bishop ${ }^{1}$ explica, o estágio 7 visa, portanto, alertar para as barreiras para aderir uma nova ideia. Nessa fase é fundamental analisar os fatores que poderiam afetar a implementação de intervençóes no campo e estruturar estratégias para minimizá-los. Uma recomendação que vale destaque, nesse sentido, para essa fase, é a adoção de uma estratégia, cuja aplicação favorecerá uma análise mais detalhada e real sobre as barreiras que serão 
encontradas. Por exemplo, a implementação de um "projeto piloto", no qual os pesquisadores, treinadores e atletas possam "experimentar" os procedimentos e analisar o resultado em diferentes perspectivas. Essa abordagem poderia enfatizar a importância do projeto para os treinadores e atletas, esclarecendo quais seriam as possíveis vantagens da adoção da estratégia investigada. Esse tipo de ação poderia aproximar cientistas e treinadores, deixando claro que o objetivo final não seria somente "coletar dados", mas auxiliar nos procedimentos e colaborar com a melhoria da qualidade do processo de treinamento como um todo. Esse cenário poderia favorecer a adoção do modelo de pesquisa, reduzindo as barreiras e aproximando os "atores" envolvidos no processo. É preciso alterar a visão dos profissionais do Esporte que os cientistas estáo simplesmente "correndo atrás" de dados para suas pesquisas, bem como, os cientistas precisam entender que a coleta de dados faz parte do processo, mas não é a principal finalidade.

\section{Fase 8 - Implementação no ambiente esportivo real}

O último estágio tem como objetivo a implementação e a avaliação de uma intervenção no cenário esportivo real. Isto é, quão eficaz é a intervenção cientificamente comprovada (desenvolvido a partir das etapas anteriores), quando aplicada à população alvo, dentro das limitaçóes de tempo e recursos limitados, com níveis de conhecimento diferentes da comissão técnica e as outras atividades realizadas pelos atletas? Os delineamentos metodológicos destes estudos podem conter maior variação de erro ou fontes de viés, quando comparados às condições controladas. No entanto, BisHop ${ }^{1}$ acredita que os resultados obtidos tendem a ser mais relevantes e com maior probabilidade de adoção pelos profissionais do Esporte.

Bishop $^{1}$ ainda ressalta que as colaboraçóes entre pesquisadores academicamente treinados e profissionais que têm experiência com o trabalho de campo sáo essenciais para a realizaçáo dos estudos do "mundo real". Tal colaboraçáo deveria funcionar ao contrário da configuração tradicional, na qual cientistas tendem a trabalhar em seus próprios domínios e não se comunicar bem com os profissionais que possuem a experiência empírica. Nesse sentido, Moreira ${ }^{11}$ enfatiza que os pesquisadores precisam se aproximar dos profissionais do Esporte, em diferentes instâncias (da iniciação ao alto rendimento), buscando ser cada vez mais críticos com os dados coletados, fazendo perguntas de pesquisa, realmente, relevantes para a situação em questão, contextualizando essas informaçôes com o auxílio dos profissionais que vivem o dia a dia do Esporte. Moreira ${ }^{11}$ ressalta que desta forma seria possível ampliar a utilidade da informação gerada, estreitar as relaçóes com o "consumidor final" do conhecimento gerado na academia, garantir a integridade da disciplina acadêmica e, ainda, manter a qualidade da produção científica na área.

Outro ponto importante que deve ser destacado com relação a essa última fase está relacionado à interpretação dos resultados de testes de eficácia. Alguns fatores potencialmente relevantes para o desempenho poderiam náo ser reconhecidos devido à aplicação incorreta da intervenção, às variáveis de confusão ou ao fraco nível de aceitação/adesão dos participantes ${ }^{1}$.

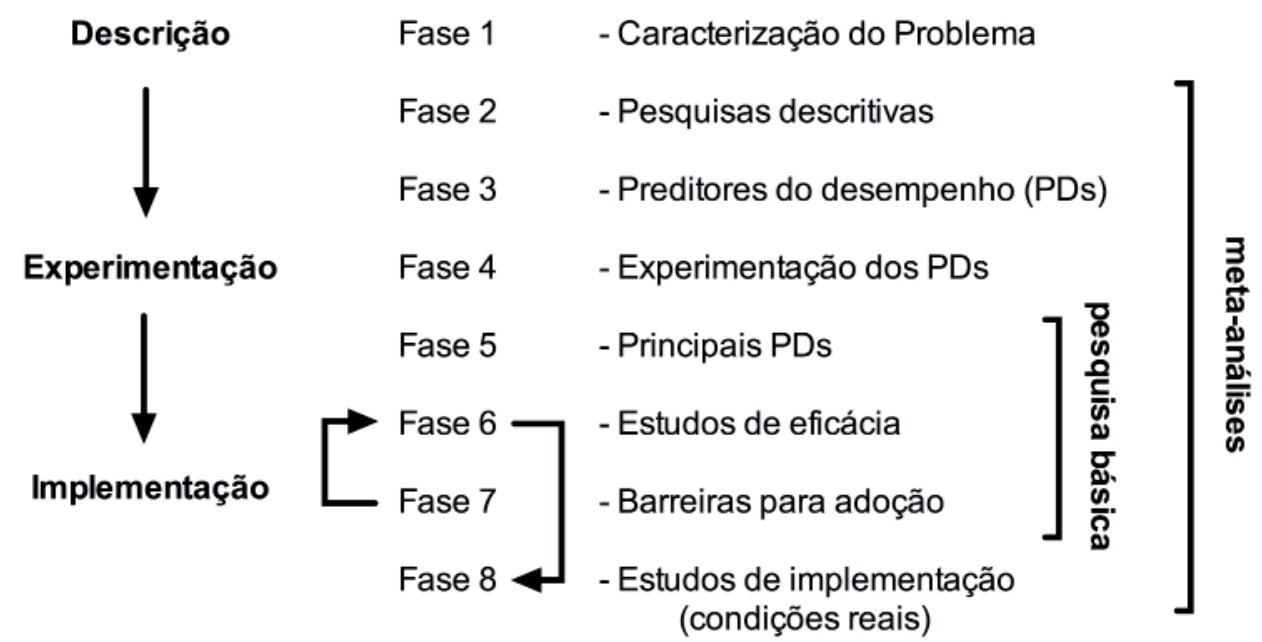

FIGURA 1 - Modelo para o desenvolvimento de pesquisa aplicada, proposto por BishoP 


\section{Aplicando o modelo de pesquisa}

Além de revisitar o modelo proposto por Bishop ${ }^{1}$, o presente ensaio apresenta uma proposta de aplicação do mesmo no cenário nacional. Conforme já mencionado, anteriormente, as diretrizes sugeridas por BisHOP ${ }^{1}$ podem promover a aproximação entre o conhecimento científico e a prática.

Com base neste modelo, recentemente, o nosso grupo de pesquisa realizou alguns estudos com referência ao Tênis. Inicialmente, após identificar queixas referentes à redução do desempenho em partidas com maior duraçáo (Problema), por parte de treinadores e atletas, o nosso grupo conduziu um estudo de caso com dois dos melhores tenistas brasileiros (simples) no "ranking" da $\mathrm{ATP}^{12}$. O referido estudo teve como objetivo investigar as demandas fisiológicas de tenistas durante a preparação para a Copa Davis de 2008. Este estudo foi publicado no European Journal of Sports Science ${ }^{12}$ (Estágio de descriçáo). Com base nas informaçóes obtidas, o nosso grupo de pesquisa levantou questionamentos sobre as condutas nutricionais adotadas (ex. hidratação) e as estratégias de treinamento (padrão de intensidade e densidade das sessóes de treinamento). A partir desse estudo, na mesma linha descritiva, o nosso grupo publicou outro estudo de caso na Revista Brasileira de Cineantropometria e Desempenho Humano ${ }^{13}$, que teve como objetivo determinar a carga interna de treinamento durante sessōes de treinamento e competição (Estágio de descriçáo). Esta comparação entre as cargas de treinamento e as cargas de competição foi utilizada pelo nosso grupo para investigar a especificidade do treinamento, servindo como "feedback" para treinadores e preparadores físicos. Nós também publicamos outro artigo na Revista Brasileira de Medicina do Esporte ${ }^{14}$, no qual o perfil antropométrico e a ingestáo dietética foram analisados em tenistas amadores e profissionais
(Estágio de descriçáo). Após a análise da dieta, identificamos a baixa ingestáo de carboidrato por parte dos tenistas ${ }^{14}$. Este dado nos levou a investigar o efeito da suplementaçáo de carboidrato sobre desempenho destes atletas. Apesar da suplementação de carboidrato ser uma estratégia extremamente popular entre os atletas, poucos estudos investigaram o efeito desta manipulação dietética no Tênis. Além disso, os poucos estudos disponíveis apresentam resultados controversos. Estes achados foram resumidos em uma revisão de literatura e, posteriormente, publicados na Revista Brasileira de Medicina do Esporte ${ }^{15}$. Uma vez que o efeito da suplementação de carboidrato permanece controverso, nós decidimos conduzir um estudo para verificar se a suplementação de carboidratos é capaz de influenciar respostas fisiológicas e o desempenho de tenistas. Esta investigação seguiu o modelo randomizado, duplo cego e cruzado, no qual os mesmos indivíduos jogaram uma partida de Tênis por três horas, recebendo solução placebo ou solução de carboidrato, em duas situaçóes diferentes (Estágio de experimentação). Uma parte destes resultados foi publicada recentemente no Journal of the International Society of Sports Nutrition ${ }^{16}$ e a segunda parte desse estudo foi publicada no Journal of Strength and Conditioning Research ${ }^{17}$. Nesses estudos, a suplementação de carboidrato não afetou o desempenho dos tenistas, entretanto, o consumo da solução de carboidrato atenuou a secreção de cortisol em relação ao consumo da soluçáo placebo. Os resultados desses estudos de experimentação foram utilizados para modificar as estratégias nutricionais dos tenistas na prática. O nosso grupo continua testando/investigando outras estratégias potencialmente ergogênicas para tenistas, visando implementar essas condutas na prática (Estágio de implementaçáo).

\section{Qual é o cenário atual no Brasil e quais são as novas perspectivas?}

O Esporte brasileiro há algum tempo vem se destacando no cenário internacional, com resultados significativos em algumas modalidades esportivas. Esses resultados foram conquistados pelo talento individual dos atletas brasileiros, os quais são estimulados e motivados desde muito cedo a atingirem o alto rendimento esportivo, com o apoio de treinadores capacitados e instituiçóes voltadas para o suporte e incentivo destes atletas. Apesar destes esforços, não existe no país um sistema de desenvolvimento esportivo, direcionado para a detecção de talentos, monitoramento e aprimoramento desses talentos, visando à formaçáo das futuras geraçôes de atletas. Nesse contexto, é imprescindível implantar um sistema de desenvolvimento do Esporte, que possibilite a integraçáo do conhecimento científico e a prática, desde a sua base até o rendimento máximo. 
Para refletir sobre o Esporte, é preciso pensar além dos resultados competitivos. É fundamental analisá-lo como um fenômeno complexo, que sofre a influência de diversos aspectos sociais, educacionais e culturais tais como: histórico de vida do atleta e de sua família, comissão técnica, apoio financeiro, infraestrutura de treinamento, suporte científico-tecnológico, entre outros. Essa complexidade inerente ao Esporte exige, cada vez mais, uma abordagem multi, inter e intradisciplinar, contando com diferentes áreas do conhecimento, para a busca dos melhores resultados.

A competitividade do Esporte contemporâneo e a minúscula diferença que separa os principais atletas fazem com que a investigação científica eficiente seja cada vez mais necessária. Em alguns casos, foram demonstrados valores médios nos resultados entre os medalhistas inferiores a $0,5 \%$. Nos Jogos Olímpicos de Sydney (2000), por exemplo, a diferença entre o tempo do medalhista de ouro etíope Haile Gebreselassie e do queniano medalha de prata Paul Tergat foi de $0,005 \%$. O medalhista de bronze, o também etíope Assefa Mezgebu, terminou a prova com uma marca apenas $0,04 \%$ abaixo do vencedor. Tais dados ilustram o conceito de que a busca pela excelência e a vitória nos Jogos Olímpicos passa pela observação criteriosa dos mínimos detalhes, que podem ser cruciais para diferenciar os vencedores de seus pares. Neste contexto, o conhecimento científico pode ser um fator decisivo para o aumento do desempenho atlético.

No Brasil, um marco inicial para a valorização do Esporte foi a criação do Ministério do Esporte, em $2003^{18}$. No entanto, Ferreira ${ }^{18}$ ressalta que em comparação a outros países (Alemanha, Austrália, China e Estados Unidos), o investimento do governo brasileiro no Esporte é incipiente. FerreIra ${ }^{18}$ ainda destaca que no Brasil não existe um instituto governamental específico para apoiar/fomentar o Esporte. $\mathrm{Na}$ tentativa de suprir essa lacuna, o Ministério do Esporte, por meio da Secretaria de Alto Rendimento, estabeleceu a criaçáo de uma rede em parceria com as universidades públicas e com o Comitê Olímpico do Brasil (COB), para a busca pela excelência esportiva ${ }^{18}$. A rede de 14 universidades foi intitulada de Rede CENESP, cuja atividade atingiu seu ápice nos Jogos Pan Americanos do Rio 2007 e nos Jogos Olímpicos de Beijing 2008. O objetivo da Rede CENESP foi fornecer suporte para o processo de avaliaçáo e treinamento de atletas, com o uso de recursos materiais (equipamentos e laboratórios de pesquisa) e recursos humanos das universidades, em diferentes regiôes do país e do exterior. No final de 2006, o COB criou o Departamento de Ciência do Esporte, tendo em vista os Jogos Panamericanos do Rio 2007 e os Jogos Olímpicos de Pequim 2008, que em conjunto com a Rede CENESP realizou acompanhamento periódico de 200 atletas da missão brasileira em ambos eventos esportivos. O objetivo do Departamento de Ciência do Esporte do COB foi fornecer apoio aos atletas de modo aplicado, tentando estabelecer a conexão entre o conhecimento científico e os treinadores esportivos. Além disso, novas tendências e tecnologias utilizadas para maximizar o desempenho dos atletas foram investigadas, tendo como base o modelo australiano. Essa aproximação e contextualização permitiram que o Departamento de Ciência do Esporte do COB e a Rede CENESP realizassem testes e avaliaçóes no campo de treinamento, aumentando a especificidade e aplicabilidade dos resultados obtidos. Essa iniciativa do $\mathrm{COB}$ em parceria com o Ministério do Esporte propiciou o atendimento aos atletas com maior suporte científico. A realização dos testes e avaliaçoóes com os atletas de elite, nessa última década, também possibilitou a aproximação da Ciência do Esporte com os profissionais de campo, gerando conhecimento. Contudo, esse ainda é o primeiro passo do modelo, ou seja, a fase de descrição. Agora, é preciso avançar, ordenadamente, para as fases de experimentação e implementaçáo. Dessa forma, será possível buscar soluçóes embasadas no conhecimento científico, a fim de criar uma prática baseada em evidência.

Alguns pontos ainda são barreiras para aproximar o conhecimento científico do contexto prático do Esporte brasileiro, destacando-se: o conflito de interesses entre os pesquisadores e a comissão técnica (publicações vs. medalhas), a morosidade da produção do conhecimento científico e o imediatismo inerente ao Esporte, a inexistência de linhas de fomento à pesquisa destinada ao Esporte, a dificuldade na publicação dos resultados em periódicos da área e a grande cobrança do sistema acadêmico-científico por publicaçóes de alto impacto.

Com relação aos dois últimos tópicos, as pesquisas que utilizam atletas como amostra são, frequentemente, criticadas pelo fato da amostra ser, relativamente pequena ou pelo fato do delineamento experimental não seguir o modelo dos estudos randomizadoscruzados com grupo controle. Mas, qual seria o grupo controle ideal para a Seleção Brasileira de Futebol? Um grupo de universitários saudáveis que participa da "pelada" de fim de semana? Qual grupo de atletas de elite aceitaria interromper a sua rotina de treinamento para ser utilizado como grupo controle? Qual comissão técnica aceitaria submeter seus atletas a procedimentos experimentais cruzados durante a 
temporada competitiva? Em uma publicação sobre os desafios da Ciência do Esporte, STONE et al. ${ }^{10}$ afirmam que o delineamento experimental "pré vs. pósintervenção com grupo controle”, frequentemente, utilizado nas pesquisas relacionadas aos benefícios do exercício físico no contexto da saúde, não é factível no contexto do Esporte. Segundo STONE et al. ${ }^{10}$ "atletas por definição são indivíduos únicos; portanto, conseguir um grupo controle comparável seria quase impossível". Logo, o tamanho da amostra sempre será restrito neste tipo de pesquisa e nem sempre será possível compor o grupo controle apropriado. Mais uma vez, é importante salientar essas especificidades da área para que os revisores e os editores dos periódicos comecem a considerar essas "limitaçôes" ao julgar este tipo de investigação.

Já no que concerne às linhas de fomento para a pesquisa, duas iniciativas recentes precisam ser mencionadas, a primeira foi a escolha do tema para o XXVI Prêmio Jovem Cientista (2012), "Inovação Tecnológica para o Esporte”. Posteriormente, a segunda foi o edital do CNPq (91/2013) "Seleção pública de projetos de pesquisa científica, tecnológica e de inovação, voltados para o desenvolvimento do Esporte em suas diferentes dimensóes". Esse tipo de iniciativa, por parte do CNPq, é fundamental para o desenvolvimento da Ciência do Esporte no Brasil. Entretanto, essas açóes precisam ser mantidas e expandidas para outras agências de fomento. Adicionalmente, cabe também ressaltar que a avaliação dos projetos e a pertinência dos mesmos para as alíneas disponíveis devem ser aperfeiçoadas. Os avaliadores destes projetos precisam ser orientados por um modelo centrado no desenvolvimento da Ciência do Esporte, de fato. $\mathrm{O}$ julgamento do mérito dos projetos enviados, portanto, deveria incluir uma perspectiva direcionada para o desenvolvimento das pesquisas que tem como objeto de estudo o Esporte, visando maximizar o desempenho dos atletas. É preciso encontrar mecanismos que tornem essa análise mais eficaz, pois muitos projetos efetivamente associados à Ciência do Esporte podem ser preteridos, favorecendo a indicação de outros projetos que, apesar de bem estruturados e importantes para a área da saúde como um todo, utilizam somente o "esporte" como "pano de fundo".
A realização dos grandes eventos esportivos no Brasil levantou a necessidade de uma preparação adequada de profissionais ligados ao Esporte, assim como, do desenvolvimento de áreas técnicas e científicas. Diante dessa necessidade, outra ação, relativamente recente, proposta pelo Instituto Olímpico Brasileiro (COB), foi a criação a Academia Brasileira de Treinadores (ABT), em meados de 2012. O objetivo da ABT, segundo o $\mathrm{COB}$, é melhorar o sistema de preparação esportiva no país, preenchendo a carência na formação do treinador esportivo de alto rendimento. Essa é mais uma ação implementada pelo $\mathrm{COB}$ para tornar e manter o Brasil uma potência olímpica. Apesar do mérito da ação, é fundamental avaliar de forma continuada a real efetividade e eficácia da ABT. Questóes essenciais deveriam ser alvo de avaliação, como por exemplo, se a prática do treinador está sendo realmente qualificada e se o conteúdo desenvolvido na ABT está de acordo com as expectativas e, principalmente, com as demandas dos treinadores. Adicionalmente, seria desejável avaliar o efeito desta ação na Ciência do Esporte propriamente dita e se o seu desenvolvimento estaria sendo estimulado e aperfeiçoado a partir desta ação.

De todo modo, não resta dúvida que o Brasil ainda está trilhando os primeiros passos na jornada da Ciência do Esporte, mas é importante ressaltar que outros países já percorreram esses caminhos há muito tempo, utilizando o suporte científico para o desenvolvimento do Esporte. Estes países criaram centros de treinamento, nos quais atletas e seus treinadores trabalham com cientistas direcionados, exclusivamente, a resolver seus problemas. As perspectivas futuras, com a realização dos Jogos Olímpicos para o Brasil, ficam por conta da estruturação de Centros de Treinamento, inseridos no contexto atual do Esporte nacional, com um planejamento a longo prazo, no qual o conhecimento gerado possa ser padronizado e implementado em diferentes Estados do país, por núcleos de desenvolvimento e aperfeiçoamento. Além disso, têm sido discutida a criação de uma Universidade (ou Instituto Federal Tecnológico) do Esporte, utilizando as instalaçóes construídas para os Jogos Olímpicos Rio 2016. 


\title{
Considerações finais
}

Não há garantia de que a aplicação deste modelo de investigação proposto irá melhorar o desempenho esportivo. No entanto, a abordagem do modelo apresentado estimula a construção do conhecimento científico, com maior chance de aplicação prática. Não reconhecer essa necessidade de aplicar o conhecimento gerado na prática, é algo similar a aceitar que engenheiros passem a investigar somente questôes pertinentes à Física e à Matemática, ou que médicos se preocupem única e exclusivamente com o conhecimento e a investigação referente à Bioquímica ou à Biologia. Portanto, assim como parece ser razoável admitir que estes pesquisadores devam conduzir estudos com aplicação prática, também parece ser pertinente que os cientistas do Esporte conduzam, de forma eficaz, seus projetos de pesquisa, possibilitando a integração entre a teoria e a prática. Além disso, apesar dos avanços tecnológicos, as ferramentas mais simples, que podem ajudar a responder muitos questionamentos da prática, náo devem ser descartadas em detrimento da parafernália tecnológica. É possível afirmar que a Ciência do Esporte no Brasil ainda se encontra em uma fase embrionária, em comparação a outros países mais desenvolvidos. No entanto, vale destacar os importantes avanços alcançados na última década. Para o futuro seria desejável a proposição de novas abordagens e modelos para minimizar a distância entre ciência e a prática, a revisão/alteração do processo de formação dos novos pesquisadores e profissionais do Esporte, a reciclagem dos pesquisadores e profissionais mais experimentes e o surgimento de políticas públicas de incentivo à pesquisa no Esporte. Essas açôes conjuntas são fundamentais para facilitar o desenvolvimento da Ciência do Esporte no Brasil.

\section{Nota}

O autor Luís Viveiros é aluno do Programa de Pós-graduação em Neurologia do Centro de Ciências Biológicas e da Saúde da Universidade Federal do Estado do Rio de Janeiro.

\begin{abstract}
Sport Science in Brazil: considerations regarding research development, current scenario, and new perspectives

Brazil has recently hosted one of the most important sports events in the world, the 2014 Soccer World Cup, and in a near future will host the 2016 Rio Olympic Games. These events may be considered as a great opportunity to develop Sport Science in Brazil. Sport Science can be defined by a scientific process used to guide the practice of sport with the ultimate aim of improving sporting performance. However, despite this goal, the general consensus is that Sport Science research is not currently informing/guiding sport practice. This essay revisits the model for developing Sports Science proposed earlier by BIsHoP', discusses the Sport Science scenario in Brazil, and also pointed out the future perspectives. The directions from the revisited model in conjunction with the discussions undertaken in this essay may aid a sport scientist to develop applied studies which results might be adopted to guide sport practice and maximize performance.
\end{abstract}

KEY WoRDS: Researchers; Evidence-based practice; Sports coaches; Athletic performance. 


\section{Referências}

1. Bishop D. An applied research model for the sport sciences. Sports Med. 2008;38:253-63.

2. Bishop D, Burnett A, Farrow D. Sports-science roundtable: does sports-science research influence practice. Int J Sports Physiol Perform. 2006;1:161-8.

3. Coutts AJ. In the age of technology, Occam's razor still applies. Int J Sports Physiol Perform. 2014;9:741.

4. Gyani A, Shafran R, Myles P, et al. The gap between science and practice: how therapists make their clinical decisions. Behav Ther. 2014;45:199-211.

5. Ajani K, Moez S. Gap between knowledge and practice in nursing. Procedia - Soc Behav Sci. 2011;15:3927-31.

6. Williams J, Kendall L. Perceptions of elite coaches and sports scientists of the research needs for elite coaching practice. J Sports Sci. 2007;25:1577-86.

7. Reade I, Rodgers W, Hall N. Knowledge transfer: how do high performance coaches access the knowledge of sport scientists. Int J Sports Sci Coach. 2008;3:319-34.

8. Moreira A, Bilsborough JC, Sullivan CJ, et al. The training periodization of professional australian football players during an entire AFL season. Int J Sports Physiol Perform. 2014 Nov 18. [Epub ahead of print]. PMID: 25405365.

9. Vandorpe B, Vandendriessche JB, Vaeyens R, et al. The value of a non-sport-specific motor test battery in predicting performance in young female gymnasts. J Sports Sci. 2012;30:497-505.

10. Stone MH, Sands WA, Stone ME. The downfall of sports science in the United States. Strength Cond J. 2004;26:72-5.

11. Moreira A. Pesquisa, produção de conhecimento, implicaçóes práticas: estamos avançando? Rev Bras Educ Fís Esporte 2014;28:359.

12. Gomes RV, Coutts AJ, Viveiros L, Aoki MS. Physiological demands of match play in elite tennis. Eur J Sport Sci. 2011;11:105-9.

13. Coutts AJ. Gomes RV, Viveiros L, et al. Monitoring training load in elite tennis. Rev Bras Cineantropom Des Hum. 2010;12:217-20.

14. Gomes RV, Ribeiro SML, Veibig RV, et al. Consumo alimentar e perfil antropométrico de tenistas amadores e profissionais. Rev Bras Med Esporte. 2009;15:436-40.

15. Gomes RV, Aoki MS. A suplementação de carboidrato maximiza o desempenho de tenistas? Rev Bras Med Esporte. 2010;16:67-70.

16.Gomes RV, Capitani CD, Ugrinowitsch C, et al. Does carbohydrate supplementation enhance tennis match play performance? J Int Soc Sports Nutr. 2013;10:46.

17. Gomes RV, Moreira A, Coutts AJ, et al. Effect of carbohydrate supplementation on the physiological and perceptual responses during prolonged tennis match play. J Strength Cond Res. 2014;28:735-41.

18. Ferreira R L. Políticas para o esporte de alto rendimento estudo: comparativo de alguns sistemas esportivos nacionais visando um contributo para o Brasil. XV Congresso Brasileiro de Ciências do Esporte; 2007; Recife, BR. Recife: CBCE; 2007.

\section{Agradecimento}

Luís Viveiros agradece o Ministério do Esporte pela bolsa de extensão 6805 - ESEF - UFRGS, ME 2012 - Esporte de Alto Nível.

ENDEREÇO

Marcelo Saldanha Aoki

Escola de Artes, Ciências e Humanidades - USP

Av. Arlindo Bettio, 1000

03828-00o - São Paulo - SP - BRASIL

e-mail: aoki.ms@usp.br
Recebido para publicação: 14/01/2015

Aceito: 21/01/2015 